\title{
A Representação das Minorias nas Obras Literárias do Programa de Avaliação Seriada da UnB (aplicação 2019)
}

\author{
OLIVEIRA, Marcus Rodolfo Bringel de ${ }^{1}$ \\ PEREIRA, Claudio Alves ${ }^{2}$
}

\section{RESUMO}

Tendo em vista a relevância das obras literárias para o planejamento didático e o trabalho docente dos professores da disciplina de Língua Portuguesa, este artigo tem como objetivo analisar como os textos indicados pelo programa de seleção da Universidade de Brasília contemplam a presença ou reforçam a ausência das minorias, dialogando, atualizando ou revisando o cânone literário. Para tanto, buscou-se analisar a relevância dos vestibulares na programação de ensino, o papel do cânone no ensino da literatura, bem como tal entidade é decisiva na representação e recepção das minorias no texto literário, e as possibilidades de atualização didática desses elementos de ensino para uma educação que considere as minorias de forma mais inclusiva ou como produtoras de literatura. Essa discussão procura nortear as possíveis discussões em sala de aula e a conscientização final acerca desses grupos na sociedade, de modo a promover a formação de sujeitos críticos e conscientes.

Cânone. Representação. Minorias. Vestibular.

\section{The representation of minorities in the literary works of the UnB Serial Evaluation Program (application 2019)}

\section{ABSTRACT}

In view of the construction of literary works for didactic planning and the teaching work of teachers of the Portuguese language discipline, this article aims to analyze the texts indicated by the selection program of the University of Brasília contemplate the presence or reinforce the absence of minorities, dialoguing, updating or revising the literary canon. To this end, we sought to analyze the vestibular research in teaching programming, the role of the canon in the teaching

\footnotetext{
${ }^{1}$ Pós-graduando em Docência na Educação Básica pelo Instituto Federal Minas Gerais. Mestre em Literatura pela Universidade de Brasília. E-mail: marcus.bringel87@gmail.com. Lattes: http://lattes.cnpq.br/1840061122510553. Orcid: https://orcid.org/0000-0003-2976-6061.

${ }^{2}$ Doutorando em Educação pela Universidade Federal do Espírito Santo. Mestre em Educação pela Universidade Federal de Lavras. Professor no curso de Pós-Graduação em Docência no Instituto Federal Minas Gerais. E-mail: claudioapessoal@gmail.com. Lattes: http://lattes.cnpq.br/6757652025792854. Orcid: https://orcid.org/0000-0002-4829-6272.
}

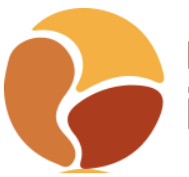

Interritórios | Revista de Educação Universidade Federal de Pernambuco, Caruaru, BRASIL | V.6 N.12 [2020] 
of literature, as well as this entity is decisive in the representation and reception of minorities in the literary text, and as possibilities for didactic updating of these elements of teaching for an education that considers minorities in a more inclusive way or as producers of literature. This discussion seeks to guide how possible it occurs in the classroom and the final awareness about these groups in society, in order to promote the formation of standards and conscious.

Canon. Representation. Minorities. Entrance exams.

\section{La representación de las minorías en las obras literarias del “Programa de Avaliação Seriada” de la UnB (aplicación 2019)}

\section{RESUMEN}

Dada la relevancia de las obras literarias para el planeamiento didáctico y el trabajo docente de los profesores de la asignatura de Lengua Portuguesa, este artículo tiene como objetivo analizar cómo los textos indicados por el programa de selección de la Universidad de Brasilia contemplan la presencia o refuerzan la ausencia de las minorías, dialogando, actualizando o revisando el canon literario. Para ello, se buscó analizar la relevancia de las pruebas de acceso en la programación de enseñanza, el papel del canon en la enseñanza de la literatura, así como esta entidad es determinante en la representación y recepción de las minorías en el texto literario, y las posibilidades de actualización didáctica de estos elementos de la la enseñanza para una educación que considere a las minorías de manera más inclusiva o como productoras de literatura. Esta discusión busca orientar las posibles discusiones en el aula y la conciencia final sobre estos grupos en la sociedad, con el fin de promover la formación de sujetos críticos y conscientes.

Canon. Representación. Minorías. Vestibular.

\section{La rappresentanza delle minoranze nelle opere letterarie del “Programa de Avaliação Seriada” dell'UnB (candidatura 2019)}

\section{SOMMARIO}

Data la rilevanza delle opere letterarie per la pianificazione didattica e il lavoro di insegnamento dei professori della materia Lingua portoghese, questo articolo si propone di analizzare come i testi indicati dal programma di selezione dell'Università di Brasilia contemplano la presenza oppure rafforzano l'assenza di minoranze, dialogando, aggiornando o rivedendo il canone letterario. Per fare questo, abbiamo cercato di analizzare la rilevanza degli esami di ammissione nella programmazione dell'insegnamento, il ruolo del canone nell'insegnamento della letteratura, così come questa entità è decisiva nella rappresentazione $e$ ricezione delle minoranze nel testo letterario, e le possibilità di aggiornamento didattico di questi elementi dell'insegnamento per un'educazione che consideri le

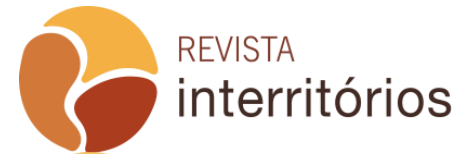


minoranze in modo più inclusivo o come produttrici di letteratura. Questa discussione cerca di guidare possibili discussioni in classe e la consapevolezza finale su questi gruppi nella società, al fine di promuovere la formazione di temi critici e consapevoli.

Canon. Rappresentazione. Minoranze. Vestibolare.

\section{INTRODUÇÃO}

O presente trabalho propõe a discussão e a análise da seleção de obras literárias apresentada no Programa de Avaliação Seriada da Universidade de Brasília, particularmente aquelas direcionadas ao segundo ano do Ensino Médio. Com efeito, o exame aqui proposto parte do grau de destaque que os concursos vestibulares, e este particularmente, têm na previsão de atividades e no direcionamento metodológico em sala de aula, sendo elemento determinante da práxi pedagógica.

$\mathrm{Na}$ ótica aqui empreendida, a argumentação parte da posição ocupada pelas obras indicadas perante o cânone literário, bem como do ponto de vista exposto na representação das personagens de acordo com a teoria literária. Tal caminho analítico dirige-se à percepção de como os grupos minoritários (como mulheres, negros e homossexuais) são apresentados no tecido literário e como essa perspectiva dialoga com o momento histórico dos textos e a percepção de tais coletivos pelo autor desses produtos artísticos.

Para esse fim, a discussão percorre diferentes facetas da literatura como parte do mundo social, debatendo questões como a expressão do cânone em relação à escolarização, a questão da representação entre aspectos como identidade e diferença e o lugar do professor e do aluno diante do texto, tanto como receptores quanto como agentes das obras de arte. Como resultado, espera-se que os apanhados teóricos e analíticos aqui demonstrados sirvam para guiar a atividade docente num projeto que permita ver a Literatura como uma disciplina atual e atuante diante da diversidade e da inclusão de sujeitos não-hegemônicos, permitindo aos alunos uma educação crítica e lúcida da amplitude humana da arte.

\section{A avaliação e seu impacto educacional}

Como ferramenta de ingresso às universidades, sejam públicas ou particulares, os exames vestibulares há muitos anos já são vistos como seleções decisivas no processo de acesso ao nível superior, levando à produção de materiais próprios para sua preparação, além de cursos voltados especificamente para esse público, bem como todo um aparato didático nas 
instituições de ensino médio com direcionamento exclusivo a essa forma de certame. Por isso, percebe-se, principalmente para o ingresso nas universidades públicas - gratuitas e, por isso, mais disputadas, a importância que as diretrizes dos vestibulares têm para o encaminhamento de ensino de todas as disciplinas componentes do Ensino Médio, disputando espaço com o currículo nacional e regional de cada localidade.

No Distrito Federal e arredores, a Universidade de Brasília é a universidade pública federal de maior prestígio, apresentando três formas de acesso às suas vagas de nível superior, principalmente: o vestibular tradicional, que ocorre entre o $1^{\circ}$ e $2^{\circ}$ semestres; o Sistema de Seleção Unificada, o SiSu, que utiliza as notas do Exame Nacional de Ensino Médio (ENEM) ao final do $2^{\circ}$ semestre e para acesso no ano seguinte; e o Programa de Avaliação Seriada, também chamado de PAS, que divide as vagas com o SiSu.

Conhecida como uma das pioneiras em realizar essa forma de triagem, a Universidade de Brasília procurou unir-se à Secretaria de Estado de Educação do Distrito Federal e às escolas públicas e particulares para estabelecer uma interação entre os alunos de ensino médio e superior, buscando, assim, uma avaliação mais próxima dos conteúdos apresentados em sala de aula, tornando esse concurso mais democrático e servindo de inspiração para outras universidades realizarem exames semelhantes ${ }^{3}$.

Este sistema é uma forma de ingresso realizada ao final de cada ano letivo do Ensino Médio, num total de três provas e cujas notas serão contabilizadas na conclusão do terceiro ano para formar um ranking que dará acesso às vagas da universidade, sendo que cada etapa de seleção possui conteúdo programático próprio e, como parte dele, uma lista de obras artísticas, como músicas, peças de teatro, produções visuais, audiovisuais e textuais. Tendo em vista a Matriz de Referência do $\mathrm{PAS}^{4}$, nota-se o caráter interdisciplinar e transversal que essa seleção propõe, de maneira que os docentes de Língua Portuguesa costumam trabalhar, na disciplina de Literatura, tanto com as obras textuais como com as canções letradas, passando muitas vezes por outras referências sugeridas pelo programa, na área das Ciências Humanas.

Diante desse panorama educacional, parece prolífico repensar (ou reforçar) o papel do ensino da Literatura como disciplina crítica e conscientizadora do papel do humano em sociedade, de forma a questionar os

\footnotetext{
${ }^{3}$ CEBRASPE. Entrevista - Márcia Abrahão. Passei, Brasília, dez. 2017. Disponível em: http://www. cespe.unb.br/pas/arquivos/PASSEI_online_menor_Edicao_6.pdf. Acesso em $1^{\circ} \stackrel{ }{ } \mathrm{de}$ maio de 2020.

${ }^{4}$ CEBRASPE. Matriz de Referência do Programa de Avaliação Seriada - Segunda Etapa. 2019. Disponível em: https://cdn.cebraspe.org.br/pas/arquivos/Matriz\%20PAS\%202.pdf. Acesso em $1^{\circ}$ de maio de 2020.
} 
padrões impostos por esta e a democratizar a produção artística e sua recepção, em diálogo direto com as outras áreas do conhecimento. Nessa perspectiva de ensino, o discente deve ser capaz de compreender que "fazer literatura (...) supõe uma consciência estética que permite ao artista se colocar certos problemas sobre a realidade que ele vive ou que lhe é relatada e responder artisticamente a esses problemas" (BACCEGA, 1995, p. 74), em que se exige do sujeito-leitor (ou do aluno) a percepção, no trabalho literário, das "influências histórico-sociais daquele sociedade, manifestadas não só pela utilização da palavra enquanto matéria-prima básica de que se serve, como também pela conformação artística dessa influências, que a própria palavra lhe permite" ( $p$. 79).

Para essa análise, portanto, procura-se pensar no despertar crítico proposto por essa educação literária que permita a formação de alunos mais conscientes de sua posição no mundo, mais sensíveis às representações apresentadas no material artístico, principalmente no que se refere às minorias, num percurso analítico que permita compreender a evolução da sociedade em paralelo ao desenvolvimento da produção literária. Para tanto, optou-se por direcionar os olhares, limitados devido ao escopo do artigo, à parte das obras artísticas indicadas para o $2^{\circ}$ ano (logo, $2^{\underline{a}}$ etapa) do Processo de Avaliação Seriada da Universidade de Brasília: Cota não é esmola ${ }^{5}$, canção de Bia Ferreira; Pai contra a mãe ${ }^{6}$, conto de Machado de Assis; Úrsula ${ }^{7}$, de Maria Firmina dos Reis e Bom-crioulo ${ }^{8}$, romance de Adolfo Caminha. Esse trabalho, de tal forma, procura entender o papel do docente nessa proposta de abordagem didática "não como leitor, mas como mediador, no contexto das práticas escolares de leitura literária", num papel que o coloca entre "as preferências pessoais [e] as exigências curriculares dos projetos pedagógicos da escola" (REZENDE, 2006, p. 72).

\section{A literatura, o cânone e o ensino}

Como disciplina diretamente relacionada ao culto do bem escrever, que transmite uma forte tradição de produção artística classicamente consagrada, 0 ensino da Literatura raramente foi questionado como parte de um processo de reforço das hegemonias de representação tanto dos seus sujeitos quanto dos objetos representados que, muitas vezes, acabavam por se confundir. Segundo

\footnotetext{
${ }^{5}$ FERREIRA, Bia. Cota não é esmola. Disponível em: https://www.youtube.com/watch?v= QcQlaoHajoM. Acesso em 1ํ de maio de 2020.

${ }^{6}$ MACHADO DE ASSIS. Todos os contos. Rio de Janeiro: Editora Nova Fronteira, 2019.

${ }^{7}$ REIS, Maria Firmina dos. Úrsula. Porto Alegre: Editora Zouk, 2018.

${ }^{8}$ CAMINHA, Adolfo. Bom crioulo. São Paulo: Hedra, 2009.
}

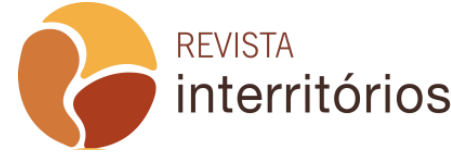


Neide Luzia de Rezende et alli (2006), "a disciplina, um dos pilares da formação burguesa humanista, sempre gozou de status privilegiado ante as outras, dada a tradição letrada de uma elite que comandava os destinos da nação" (p. 51). Esse contexto imiscui-se com o próprio cânone, cuja definição demonstra sua relação simbiótica com a escolarização em si:

O cânone literário é, assim, o corpo de obras (e seus autores) social e institucionalmente consideradas "grandes", "geniais", perenes, comunicando valores humanos essenciais, por isso dignas de serem estudadas e transmitidas de geração em geração. (...) É possível fazer remontar o estabelecimento do cânone literário enquanto instituição social à escolarização da literatura moderna, que ocorre durante o século XIX (...). Com a generalização da escolaridade obrigatória nas sociedades ocidentais, a escola passou a funcionar como o factor determinante de fixação e transmissão de cânones. (DUARTE, $2009)^{9}$.

Como reforça Fábio Lucas (1987), "a literatura escrita era um privilégio de uma classe dominante, detentora do ócio e do excedente econômico", segregando "um sistema de pensamento estabilizador de sua superioridade", de modo que "o problema social é mais ou menos recente na preocupação dos ficcionistas" (p. 09). Assim, a tradição literária consagrou, durante séculos, uma percepção das personagens e situações literárias sob a ótica da classe dominante, predominantemente branca, patriarcal, cristã e abastada, de forma que os sujeitos que não fossem identificados com essa formatação eram excluídos ou sub-representados nessas produções. Tais minorias, que são aqui entendidas como "todos aqueles que vivenciam uma identidade coletiva que recebe valoração negativa da cultura dominante" (DALCASTAGNĖ, 2012, p. 17), foram, durante a história da Literatura, apresentadas como personagens cuja representação mostrou-se problemática por não se adequar ao padrão hegemônico, resultando em uma abordagem dos grupos minoritários de forma rasa, distante ou caricatural. Dessarte,

as personagens dessas minorias, quando tratadas, são vistas antes como objeto, à luz de um olhar distante (...). O narrador, em terceira pessoa, quando muito deixa aflorar um sentimento de piedade para com as minorias, relegadas a um segundo plano. (...) Tanto uma personagem negra como indígena compõem a paisagem ou o cenário como uma árvore, um rio,

\footnotetext{
${ }^{9}$ DUARTE, João Ferreira. Cânone. E-Dicionário de Termos Literários, 29 dez. 2019. Disponível em: https://edtl.fcsh.unl.pt/encyclopedia/canone/. Acesso em 1ํ de maio de 2020. 
uma casa ou uma ferramenta: não fazem parte da essência do escritor, não habitam sua paixão. (LUCAS, 1987, pp. 33-34)

Essa permanência acrítica perdurou também na formação acadêmica de muitos professores de Língua Portuguesa, que, ainda que oriundos de classes minoritárias, reproduziram e reforçaram um cânone anacrônico e, muitas vezes, preconceituoso, sem um olhar analítico que permitisse tanto ao docente quanto ao discente reconhecer as estereotipias presentes no texto literário. Resultado dessa problemática, "na escola, o cânone em geral mantém-se, equivocadamente, estático", conservando os conteúdos da disciplina "fiéis a uma concepção cristalizada de história literária" (REZENDE, 2006, p. 75). Esse panorama demonstra a necessidade de revisão da "formação literária dos professores de Português", pois, "além de mediador da leitura, portanto leitor especializado, também se requer do professor um conhecimento mais especializado no âmbito da teoria literária" (p. 75), afastando o ensino da Literatura do "culto do estilo" ou "então, apenas como suporte de análises sintáticas e morfológicas" (p. 51).

Essa mesma falta de percepção crítica da produção literária impediu, durante muito tempo, o reconhecimento dos leitores na arte estudada, devido à falta de diversidade nos romances, mantendo a Literatura como arte idealizada, antiquada e sem diálogo direto com a realidade dos educandos. É nesse sentido que Roland Barthes (2019) afirma que a escola e as outras "instituições oficiais da linguagem são máquinas repisadoras (pois) redizem a mesma estrutura, 0 mesmo sentido, amiúde as mesmas palavras: o estereótipo é um fato político, a figura principal da ideologia" (p. 50).

Diante de uma produção artística que centraliza os caracteres dominantes da sociedade como a principal forma de representação e, portanto, de identidade, pois produzidos por autores com eles identificados, entende-se como a construção de um legado literário demonstra as relações de poder dentro da sociedade, ao silenciar, apagar, sub-representar ou, finalmente, definir o outro como a diferença. Tais padrões que cristalizam certos grupos como a identidade dominante e outros como o diferente, como se vê, "não são simplesmente definidos; eles são impostos. Eles não convivem harmoniosamente, lado a lado, em um campo de hierarquias; eles são disputados" (SILVA, 2019, p. 80). Dessa maneira, tais grupos, em situações e localizações opostas na sociedade, estão "assimetricamente situados relativamente ao poder", de modo que sua capacidade de impor-se ideologicamente e, logo, verem-se representado ou autorrepresentarem-se é frágil, pois esse conflito envolve "uma disputa mais ampla por outros recursos simbólicos e materiais da sociedade" (p. 81), culminando na construção de discursos e narrativas sociais "sobre quem pertence e sobre quem não pertence, sobre quem está incluído e quem está excluído" (p. 82).

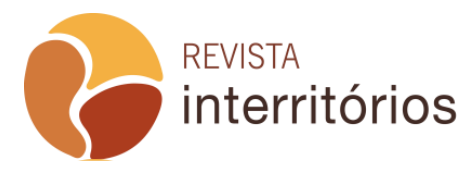

Interritórios | Revista de Educação Universidade Federal de Pernambuco, Caruaru, BRASIL | V.6 N.12 [2020] 
Enfim, localizar temporal e ideologicamente o cânone é uma perspectiva de análise literária rica, que promove uma releitura crítica da tradição artística e renova os padrões de ensino mais comuns da Literatura, permitindo que os estudantes se aproximem do conteúdo sem idealizações ou endeusamento dos seus componentes. Tal questionamento apoia-se na visão de que "analisar obras ou autores consagrados implica pensar seus próprios processos de consagração como processos históricos, que envolvem conflitos, disputas e que não são baseados em valores universais" (FACINA, 2003, p. 32). Olhar a construção da herança literária por esse viés e apresentá-la didaticamente por essa chave de leitura contribuem para uma reflexão do objeto artístico diante de sua ligação com a complexidade do momento histórico de sua produção, indo além do simples paralelismo histórico que se costuma fazer nas aulas de Língua Portuguesa. Como reitera Adriana Facina (2003), "um clássico diz respeito aos elementos que, ao longo do tempo, foram selecionados e valorizados por determinados grupos sociais e que fundamentaram tal consagração. Assim como os costumes, os padrões de gosto são diferentes em sociedades e em épocas distintas" (p. 32).

A literatura, seu ensino e seu estudo vêm passando, desse modo, por uma virada epistemológica e conceitual, que desperta uma consciência social profunda tanto na crítica quanto na produção literária e que pode ser atribuída principalmente à emergência de estudos que evidenciam a presença de grupos minoritários e sua releitura dos fatos da realidade, num "movimento que (apela) para a identidade social", o que "constitui o nascimento histórico do que veio a ser conhecido como a política da identidade" (HALL, 2006, p. 45). Nesta perspectiva de ensino de literatura, entender o poder da representação é essencial para incluir o alunado numa apreensão da arte que extrapole a simples fruição estética, mas se encaminhe para ver como as obras não são

um meio transparente de expressão de algum suposto referente. Em vez disso, a representação é, como qualquer sistema de significação, uma forma de atribuição de sentido. Como tal, a representação é um sistema linguístico e cultural: arbitrário, indeterminado e estreitamente ligado a relações de poder" (SILVA, 2019, p. 91).

Nesse entendimento, a escola tem papel central na construção de um currículo que seja capaz de "oferecer oportunidades para que as crianças e os/as jovens (desenvolvam) capacidades de crítica e questionamento dos sistemas e das formas dominantes de representação da identidade e da diferença" (SILVA, 2019, p. 91-92). Do mesmo modo que um currículo identificado com a hegemonia social reforça estereótipos minoritários, classificados como a diferença, é possível, por meio de uma abordagem educacional do problema literário 
questionadora e contestatória, a cisão desse panorama tradicionalista e estanque, na intenção de validar outras identidades e torná-las presentes no texto literário. Sob esse ponto de vista, entende-se que o contato com a alteridade é inevitável e, portanto, deve ser considerado um fator pedagógico e curricular, de forma que ele seja ouvido, visto e ocupe seu espaço na produção literária, seja como personagem ou como autor: "O outro é o outro gênero, o outro é a outra raça, o outro é a outra nacionalidade, o outro é um corpo diferente" (SILVA, 2019, p. 97).

Essa aproximação do objeto literário, do conteúdo da Literatura, do currículo escolar, do papel da escola, da função do professor e das potencialidades do educando culminam nas possibilidades de tornar tanto 0 ensino, quanto a aprendizagem "significativos para alunos e professores" (REZENDE, 2006, p. 79). Assim, validar-se-á o poder crítico de uma disciplina muitas vezes vista como alienada, reprodutora de padrões arcaicos, ao ressaltarse "a dimensão social desse conteúdo, uma vez que forma (o estudante) para o mundo", fornecendo "ao aluno recursos intelectuais e linguísticos para a vida pública" (p. 81) e, mais, como sujeito autônomo, crítico e humano.

Diante das obras indicadas no Programa de Avaliação Seriada no ano de 2019, optou-se por analisar especificamente as selecionadas para o $2^{\circ}$ ano do Ensino Médio, por entender que 0 arco de assuntos e abordagens seria mais profícuo à análise da representação das minorias no texto literário. Como resultado, dentre as diversas obras que passam por romance, poesia, teatro, canção e conto, as composições aqui discutidas focalizam, cada uma à sua maneira, as minorias sociais e trazem discursos literários e históricos que merecem ser cotejadas à luz de seu posicionamento com o cânone, de sua forma de dar voz ou silenciar os grupos excluídos da sociedade e de suas possibilidades de dialogar com estratégias de ensino multiculturais.

\section{As obras literárias e es potencialidades didáticas}

Ao entender o papel do cânone literário na sociedade, sua constituição e seu diálogo direto com o ensino escolar e a reprodução de ideologias, analisar as obras artísticas selecionadas para um exame vestibular também deve partir desse ponto de estudo para demonstrar as afiliações identitárias promovidas e discutidas pelo certame. Da mesma forma, diante da amplitude de público alcançada por esse tipo de concurso, pensar na representação das minorias empreendida pelas obras escolhidas pode mostrar ao docente um caminho de análise e conscientização crítica dos educandos que lhes permita ir além do simples prazer estético da leitura, mas alcançar, por meio das tramas e personagens, "a possibilidade de adesão afetiva e intelectual do leitor, pelos 
mecanismos de identificações, projeção, transferência, etc." (CANDIDO, 2019, p. 54).

Em ordem cronológica, o primeiro texto a ser discutido é Úrsula, de Maria Firmina dos Reis, um romance publicado em 1859 nos moldes românticos, mas que apresenta possibilidades de discussão e revisão canônica inesgotáveis. Escrito por uma mulher negra (pioneira em ambas as categorias), ainda durante a vigência da escravatura no Brasil, essa obra gozou de modesta recepção à época do seu lançamento, mas sofreu um processo de apagamento que até hoje perdura. Tanto a autora quanto a obra foram ignoradas na maioria dos manuais de literatura do século XIX e XX, só sendo retomada após a descoberta de um exemplar em 1975 e, desde então, seu reaparecimento tem se dado de modo ainda tímido mesmo nos estudos negros.

Em termos estilísticos, é uma obra que não foge aos padrões eurocêntricos e tradicionais da época do seu lançamento, contando as desventuras amorosas de um casal impedido de se unir. Entretanto, esse livro inaugura a presença de personagens negros, escravizados, em papel ainda que secundário, mas parte essencial das tramas do livro, de forma que tais figuras, além de ocuparem espaço considerável no texto, têm suas vozes e seus pensamentos ouvidos, inclusive sobre o tema da abolição que só viria a se concretizar em 1888. Tal obra adianta em décadas a poesia condoreira e, portanto, abolicionista, de Castro Alves ao focalizar a humanização de personagens negras, além de apresentar um olhar diferenciado pela autoria feminina, possibilitando representações não tradicionais à época de sua produção e, ainda hoje, como obra que revoluciona os parâmetros da história canônica da Literatura. Assim, como exercício de análise literária, essa obra permite a compreensão de como um texto elabora "a lógica das visões de mundo, dos juízos de valor e das opiniões políticas" dos escritores (FACINA, 2003, p. 46), de modo a observar que essa e outras obras são produzidas a partir do lugar de fala de seus autores e dos pontos de vista produzidos por suas experiências pessoais.

A obra seguinte, Bom-Crioulo, de Adolfo Caminha, foi publicada em 1895 como parte de um movimento literário voltado para cientificismos e determinismos muitas vezes preconceituosos, e sua narrativa espelha fielmente tais pressupostos. O livro conta a história do amor homossexual de dois marinheiros, Amaro, homem negro e mais velho, e Aleixo, jovem branco, que, diante do pensamento tendencioso da época, via a relação como uma forma de perversão, fadada, portanto, à tragédia. Apesar do discurso homofóbico e racista disfarçado de ciência, o autor elabora o primeiro romance brasileiro com protagonista homossexual e um dos romances pioneiros em posicionar um homem negro como personagem principal. É nessa dialética aparentemente paradoxal que se inscreve a literatura e, particularmente, o romance de Caminha,

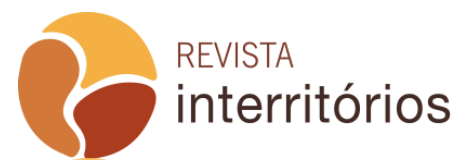


pois o discurso literário "é capaz de revelar a dinâmica complexa da realidade, através de uma grande variedade de formas que, muitas vezes, se configuram como contraditórias" (BACCEGA, 1995, p. 76-77), sendo possível, dessa forma, refratar a realidade, ressaltando suas hipocrisias e ilogicidades. A obra literária configura, dessa maneira, artisticamente os discursos ideológicos, "dando a eles novas formas, produzindo novos signos, novos conteúdos", cumprindo ela própria "um papel ideológico independente", portanto, crítico, "no momento em que retorna à realidade social de onde emergiu" (p. 78).

É justamente essa contradição fundante da realidade que aparece nas configurações narrativas do conto Pai contra mãe, de Machado de Assis, publicado em 1906. Ambientado no Brasil ainda escravocrata, a obra discute, de modo distanciado, mas, por isso mesmo, cruel, os efeitos da constituição histórica do racismo e do patriarcado no país, ao narrar o conflito entre as classes empobrecidas componentes da sociedade da época: o homem livre, mas dependente dos favores e dos trabalhos enjeitados pelos ricos, e os negros escravizados. Na trama que conta a história da perseguição de uma escrava grávida (e o aborto resultante) por um homem branco que recém se tornara pai, vê-se a discussão de uma institucionalização das violências que resultam no racismo e na misoginia ainda hoje presentes na sociedade, em que certas vidas são mais valiosas do que outras, o que dialoga diretamente com a existência de uma política atual de estado que reproduz a desumanização dos escravos no assassinato reiterado de jovens negros. Ainda que localizado no início do século $\mathrm{XX}$, o texto machadiano demonstra as possibilidades de posicionamento de um autor "no campo das lutas sociais e ideológicas", revelando, em seu discurso, como escolhe colocar-se "no sentido da manutenção dos estereótipos ou no sentido das mudanças sociais" (BACCEGA, 1995, p. 87).

Por fim, a canção de Bia Ferreira, Cota não é esmola, lançada em 2017, atualiza as discussões sobre racismo ao discutir os resultados de uma colonização exploratória e do racismo reproduzido pelas instituições oficiais do Estado na questão das cotas raciais. Ao encarar uma canção atual como texto literário, modifica-se, em termos estruturais, a noção de literatura como algo distante do alunado, aproximando seu público por meio da linguagem contemporânea, dando status de literário a um produto artístico que dialoga diretamente com a realidade vigente. Ao problematizar a meritocracia, discutindo o cotidiano da maioria da população negra brasileira, a canção propõe uma revisão da história a partir da perspectiva do excluído, de forma a possibilitar novas formas de identificação com o contexto histórico, ressaltando 0 silenciamento de personagens importantes da trajetória negra, num percurso crítico que reorganiza a compreensão das estruturas que configuram a sociedade atual. Esse texto propõe, desse modo, um ponto de vista de ensino que vá além da simples tolerância com o diferente, com o excluído, já 
reconhecido "pelo oficialismo, como legítimas questões de conhecimento" (SILVA, 2019, p. 73). Assim, nessa abordagem de ensino proposta pela canção de Bia Ferreira, há mais do que o simples reconhecimento e celebração da minoria, mas um questionamento das estruturas e das relações de poder em torno dos quais se organizam as instituições e suas práticas racistas, pois "a pedagogia e o currículo deveriam ser capazes de oferecer oportunidades para que as crianças e os/as jovens desenvolvessem capacidades de crítica e questionamento dos sistemas e das formas dominantes de representação" ( $p$. 91-92).

\section{CONCLUSÕES}

Por meio das análises e observações teóricas apresentadas, pretendeuse propor, ainda que em linhas gerais, possibilidades de abordagem educacional do ensino da Literatura que fugisse à reprodução do cânone e dos estereótipos presentes na tradição literária, de forma a abordar a seleção de livros indicados à seleção de um concurso vestibular sob "o questionamento não apenas da identidade, mas também (do) poder ao qual ela está estreitamente associada, um currículo e uma pedagogia da diferença e da multiplicidade" (SILVA, 2019, p. 101).

Para tanto, procurou-se pensar na representação das minorias presentes nessas indicações de leitura num sentido que procurasse entender, em paralelo à evolução do pensamento da sociedade brasileira, o desenvolvimento também do processo de representação. Pode-se observar, a partir da leitura e da análise de romances, conto e canção, personagens pertencentes a grupos minoritários que, inicialmente ocupavam posições que poderiam ser classificadas quase como paisagem do cenário literário. Com mudanças na autoria e na perspectiva dessas obras, as minorias passaram a ocupar um papel secundário, mas já capaz de apresentar seus pensamentos e seus pontos de vista dentro da literatura, culminando na representação como protagonistas, eivados ou não de preconceito contra esses grupos, mas numa posição que instalava imediatamente uma modificação dos padrões estéticos.

Notam-se, com esse percurso crítico e educacional, as possibilidades de instrumentalizar as categorias componentes do tecido literário para propor discussões que vão além da simples leitura e do prazer proporcionado pela estética, mas encaminhando o questionamento para rupturas que revisam 0 cânone (no caso de Úrsula, Bom-Crioulo e Pai contra mãe) ou que atualizam o cânone (no caso de Cota não é esmola). Com efeito, o papel da literatura, diante da multiplicidade de perspectivas e representações literárias, deve contribuir 
para a formação de um alunado mais consciente e crítico de sua posição como cidadão no mundo.

\section{REFERÊNCIAS}

BACCEGA, Maria Aparecida. Palavra e discurso: história e literatura. São Paulo: Ática, 1995.

BARTHES, Roland. O prazer do texto. Tradução de Jaime Ginsburg. São Paulo: Perspectiva, 2019.

CANDIDO, Antonio. A personagem do romance. In: CANDIDO, Antonio (org.). A personagem de ficção. São Paulo: Perspectiva, 2019. p. 51-80.

DALCASTAGNĖ, Regina. Literatura brasileira contemporânea: um território contestado. Vinhedo/Rio de Janeiro: Editora Horizonte/Editora da UERJ, 2012.

FACINA, Adriana. Literatura \& Sociedade. Rio de Janeiro: Jorge Zahar Editora, 2004.

HALL, Stuart. A identidade cultural na pós-modernidade. Tradução de Tomaz Tadeu da Silva e Guaracira Lopes Louro. Rio de Janeiro: DP\&A, 2006.

LUCAS, Fábio. O caráter social da ficção no Brasil. São Paulo: Ática, 1987.

REZENDE, Neide Luzia de; MACHADO, Maria Zélia Versiani \& FREDERICO, Enid Yatsuda. Conhecimentos de literatura. In: BRASIL. Orientações Curriculares para Ensino Médio: Linguagens, códigos e suas tecnologias. Brasília: Ministério da Educação/Secretaria da Educação Básica, 2006. Vol. 01. p. 49-83.

SILVA, Tomaz Tadeu da. A produção social da identidade e da diferença. In: SILVA, Tomaz Tadeu da. Identidade e diferença: a perspectiva dos Estudos Culturais. Petrópolis: Editora Vozes, 2014. p. 73-102. 